\title{
Modeling a multilevel converter for radiography and fluoroscopy
}

\author{
Juan A. Martín-Ramos, Óscar Pardo Vaquero, Juan Díaz González, Miguel A. José Prieto, \\ Juan A. Martínez Esteban, Alberto Martín Pernía \\ Universidad de Oviedo \\ Edificios Departamentales Oeste, Mod 3. \\ Campus de GIJÓN, SPAIN \\ jamartin@uniovi.es
}

\section{Acknowledgements}

This work has been funded by the Spanish Government with the action TEC2014-53324-R.

\section{Keywords}

AC/DC conversion, high voltage, resonant topologies, power stage modeling.

\begin{abstract}
In this paper a mathematical model for a resonant multilevel converter is presented. The topology has been conceived to be used in X-ray power supplies. The power stage has been designed to minimize the resonant current throughout the input voltage range: $400 \mathrm{~V}$ to $750 \mathrm{~V}$. The inverter stage is based on the series-parallel resonant topology, LCC, to include the parasitic elements of the step-up transformer. However, the introduction of an additional magnetic coupling provides a way to modify the reactive elements depending on the output power.
\end{abstract}

\section{Introduction}

A significant number of industrial applications require a power supply capable to deliver a DC voltage of tens of $\mathrm{kV}$ while transferring a power of tens of $\mathrm{kW}$. Such applications include X-ray generators, electron beam welding machines, or electrostatic precipitators to name a few. In all cases, the primary power supply is a three-phase line which may vary between $380 \mathrm{~V}$ and $480 \mathrm{~V}$ rms depending on the different regulations. Fig. 1 shows a block diagram with the usual structure of such a high-voltage power supply. The first stage is a three phase rectifier. Given the different line settings, the operating tolerances and the $50 \mathrm{~Hz}-60 \mathrm{~Hz}$ ripple, the rectifier output can take values between $400 \mathrm{~V}$ and $750 \mathrm{~V}$. The second stage is a square wave inverter where the switching frequency is in the range of tens of $\mathrm{kHz}$. This value is high enough to consider the input voltage as DC, including the low frequency ripple, and to allow the minimization of the transformer size.

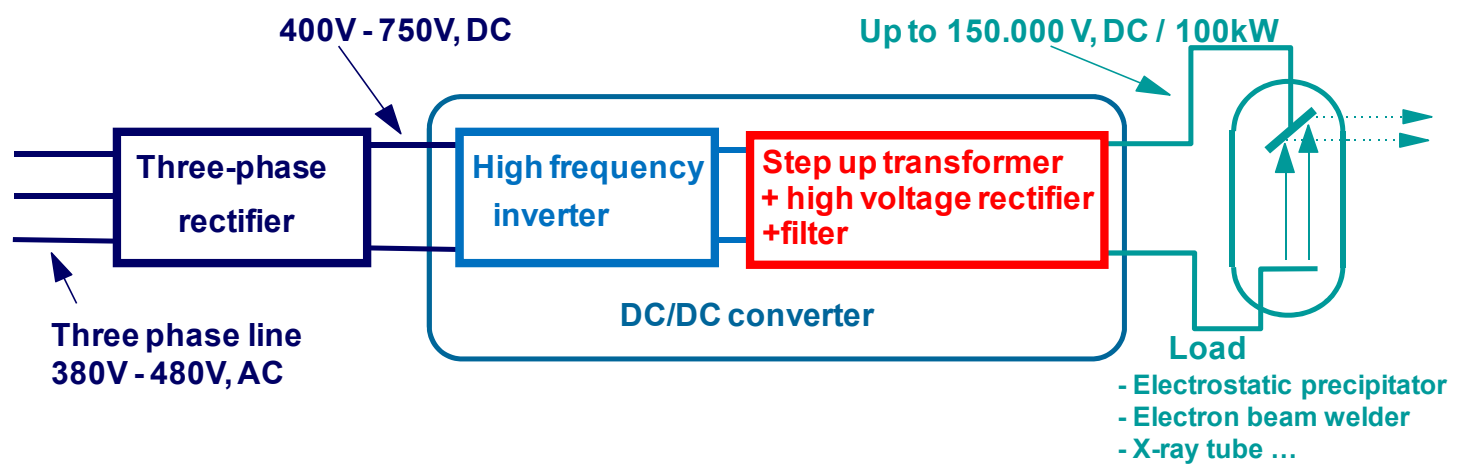

Fig. 1: Block diagram of a high voltage power supply. 
The transformer is certainly the key element in the design of this sort of power supplies. It is an essential component that provides electrical isolation and raises the output voltage to the required range: between $20 \mathrm{kV}$ and $150 \mathrm{kV}$ depending on the application. Its special features can be summarized in two consequences for topology: the presence of a leakage inductance, $\mathrm{L}_{\mathrm{S}}$, and a stray capacitance in the secondary, $\mathrm{C}_{\mathrm{P}}$; which can be transferred to primary. Both are significant [1-3]. In general, the inclusion of these reactive elements in the circuit leads to resonant topologies [4-20]. In particular, the series parallel resonant topology, PRC- LCC, with a capacitor as output filter, fig. 2, is one of the most attractive solutions, since it includes easily the transformer parasitic elements [10-17]. This paper presents a multilevel modification of this topology, which provides further versatility.

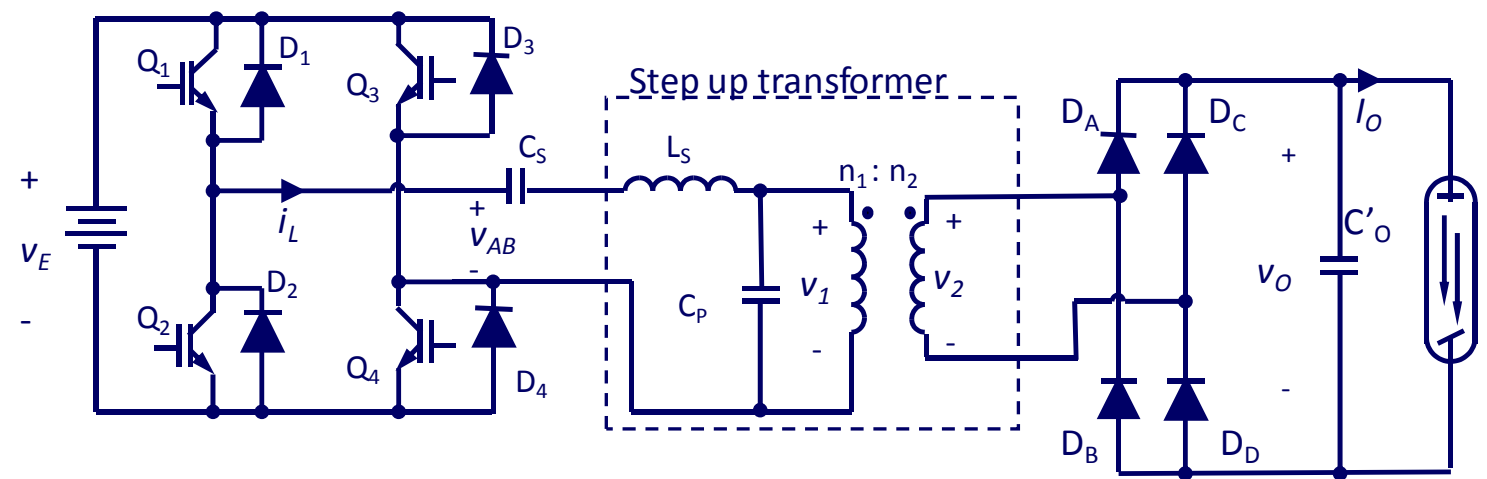

Fig. 2: Full-bridge PRC-LCC resonant topology with a capacitor as output filter. $\mathrm{V}_{\mathrm{AB}}$ is the inverter output voltage and $\mathrm{i}_{\mathrm{L}}$ is the current through the resonant inductor, $\mathrm{L}_{\mathrm{S}}$.

\section{The resonant inverter}

The performance of a full-bridge based PRC-LCC resonant converter, fig 2, is penalized because of the wide input voltage range. Obviously, the power stage must be capable of providing full power with the minimum input voltage, coping with the reactive elements of the stage. The best strategy for the converter design is to employ large duty cycles and a switching frequency close to resonance for these conditions. The ideal expected resonant current and inverter output voltage for minimum input voltage, $400 \mathrm{~V}$, and rated output power are shown in fig. 3. The resonant current is minimized due to the absence of reactive energy, and the inverter is delivering power to the load throughout the whole period. This situation is truly advantageous also from the viewpoint of the switching losses, because switching transitions always occur without current.

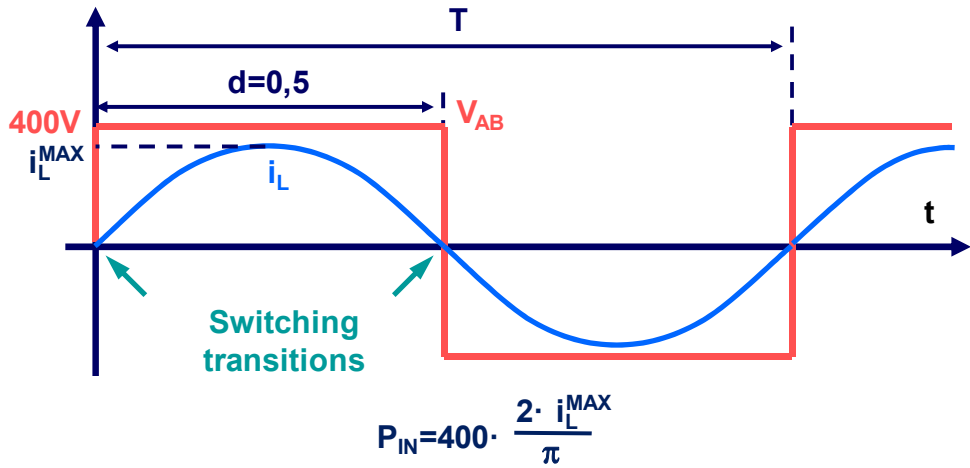

Fig. 3: Inverter output voltage and resonant current for maximum transferable power at minimum input voltage, $400 \mathrm{~V}$, in a tight design.

However, when the input voltage is not the minimum, the same inverter will be forced to change the working regime to limit the power injection into the circuit. Otherwise, the same switching frequency and duty cycle on the same circuit when the input voltage is higher will lead to higher resonant current and output power. There are three possibilities to control delivered power: a) to decrease duty cycle, b) to increase switching frequency above resonance or c) to combine both strategies, fig. 4. In any of 
those three cases, the voltage across the switches is higher, because the input voltage is above $400 \mathrm{~V}$. However, the peak value of the resonant current is not diminishing in the same proportion, although transferred power remains constant. In fact, just a $10 \%$ reduction has been measured when DC bus varies from $400 \mathrm{~V}$ to $750 \mathrm{~V}$ [8]. As a result, losses recorded on the inverter are increase largely at $750 \mathrm{~V}$. Now, switching transitions occur with high voltage and current levels, while conduction losses are not reduced.

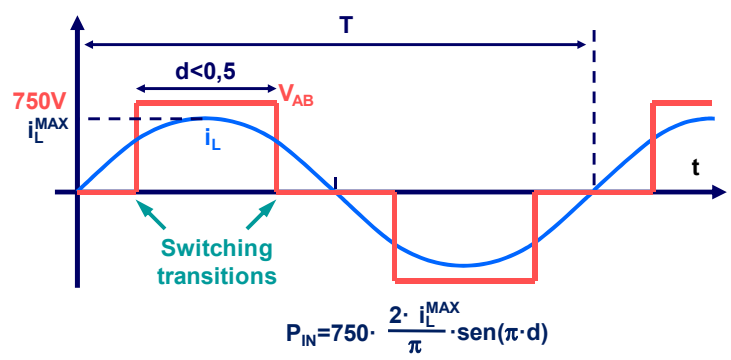

a) Staying at resonant frequency, duty cycle is reduced to maintain input power.

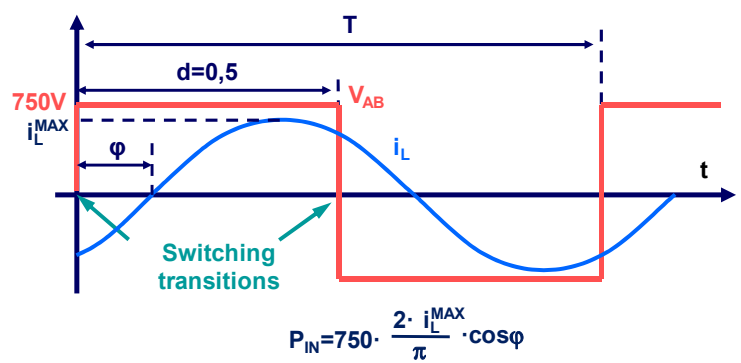

b) Duty cycle remains constant while switching frequency is increased to maintain input power.

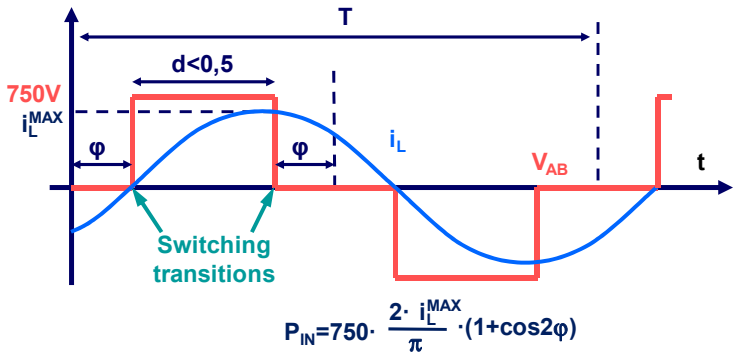

c) A particular case of switching frequency and duty cycle modification to maintain input power.

Fig. 4: Resonant current and inverter output voltage to obtain full power when the input voltage is maximum $750 \mathrm{~V}$. Three control possibilities.

The new configuration of the inverter presented in fig. 5 has been conceived to address this problem. Two full-bridges are coupled by an auxiliary transformer with a 1:1 turns ratio. As shown in fig. 6, a square waveform, $\mathrm{V}_{\mathrm{AB}}$, with up to five voltage levels is produced by them. Since the topology is resonant and the switching frequency is near resonance, the inverter output, $\mathrm{V}_{\mathrm{AB}}$, can be approximated by its first harmonic for a simple and convenient mathematical analysis. The new topology allows combining duty cycles of both inverters, to maintain constant $\mathrm{V}_{\mathrm{AB}}$ first harmonic term, independently of the DC bus level, fig. 6. Behind this new configuration also lies the possibility to optimize the value of the reactive elements to the new conditions. Now the inverter voltage is $800 \mathrm{~V}$ across the full range of input voltage, so the base impedance of the resonant circuit should be higher than the one considered for 400V. The maximum power the PRC-LCC topology can transfer is given by (1) and (2) [8]. From these expressions, it can be deduced than an increment in the minimum input voltage from $400 \mathrm{~V}$ to $800 \mathrm{~V}$ allows increasing the series inductance, $\mathrm{L}_{\mathrm{S}}$, and decreasing the equivalent capacitance, C. Having higher base impedance in the circuit involves a reduction in the resonant current. Thus, the proposed topology doubles inverter output voltage while halves resonant current to provide the same output power.

$$
\begin{aligned}
& P_{S}^{M a x}=\frac{k \cdot\left(v_{E N}\right)^{2}}{Z_{B A S E}} \\
& Z_{B A S E}=\sqrt{\frac{L_{S}}{C}} \quad \text { where } \quad C=\frac{C_{S} \cdot C_{P}}{C_{S}+C_{P}}
\end{aligned}
$$

$\mathrm{k}$ is a variable that depends on the capacitances ratio [8]. If $\mathrm{C}_{\mathrm{S}}=\mathrm{C}_{\mathrm{P}}, \mathrm{k}=4$. 
To keep constant the first harmonic amplitude of $\mathrm{V}_{\mathrm{AB}}$, the output voltage of both full-bridges is added through the auxiliary transformer, fig. 5. This control scheme is used for high power levels, i.e., radiography. However, when the output power is low, e.g. fluoroscopy, the auxiliary full bridge is kept inactive. In this case, the magnetizing inductance, $\mathrm{L}_{\mathrm{M}}$, of the $1: 1$ transformer is added to the leakage inductance, $L_{S}$, increasing the effective series inductance and the base impedance (2) of the resonant circuit, fig. 7.

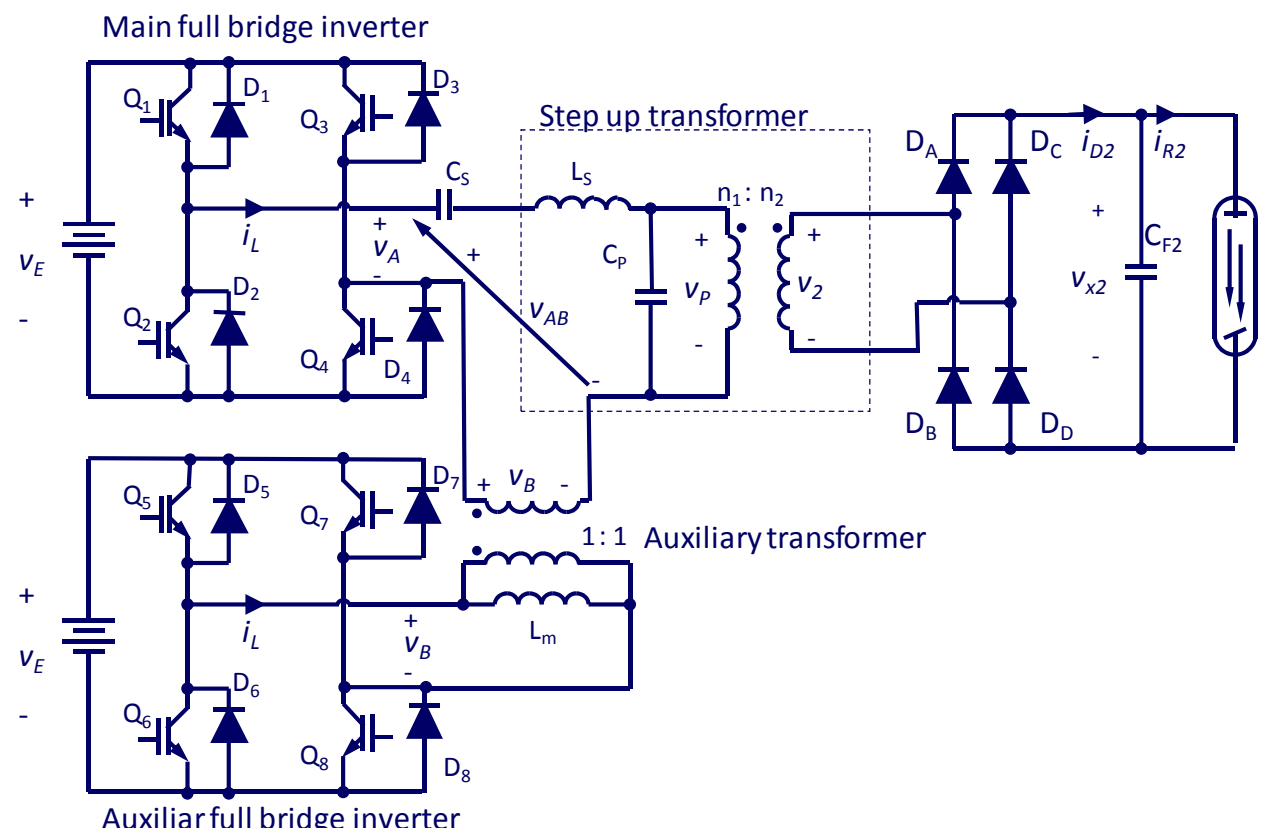

Fig. 5: Circuit for the proposed multilevel topology.
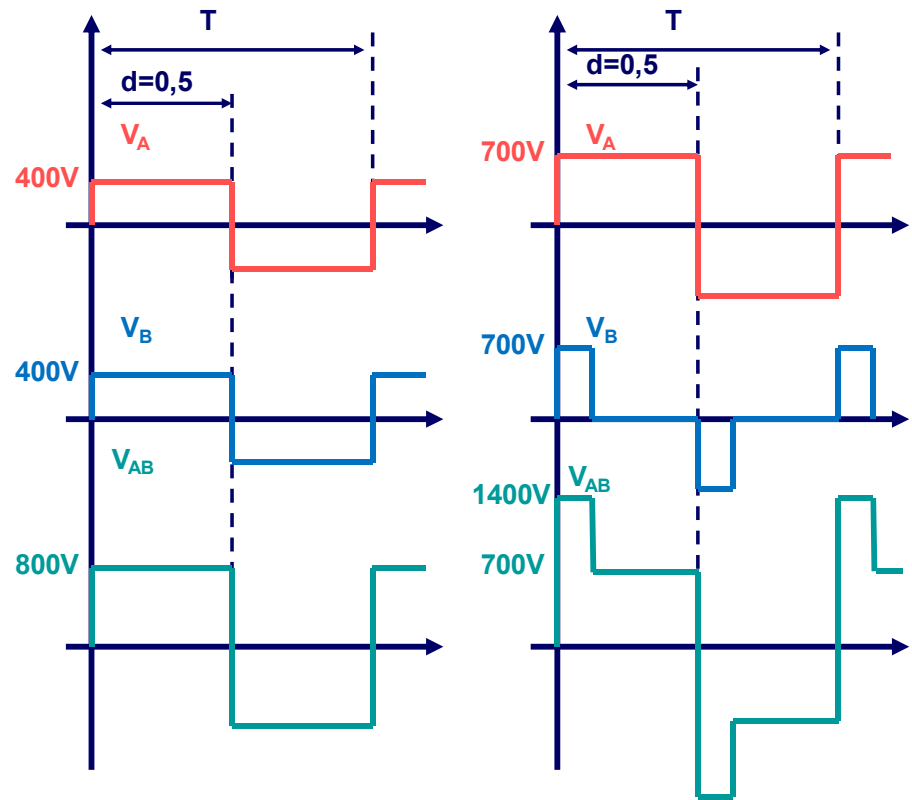

Fig. 6: Inverters duty cycles are controlled independently to maintain constant the first harmonic of $\mathrm{V}_{\mathrm{AB}}$. Example for two different $\mathrm{DC}$ bus values, $\mathrm{V}_{\mathrm{E}}=400 \mathrm{~V}$ on the left, $\mathrm{V}_{\mathrm{E}}=700 \mathrm{~V}$ on the right.

The design details for a power source based on these five voltage levels scheme, can be found in [21], where it is compared to a traditional three-level full-bridge inverter. The present work is focused on the mathematical modeling of the proposed topology. 


\section{Large signal model}

To mathematically model the topology, the resonant mesh is considered at first. This mesh presents two forms, depending on whether the auxiliary full bridge inverter is operating or not. The only difference between both cases lies in the different series inductance of the mesh, fig. 7 .

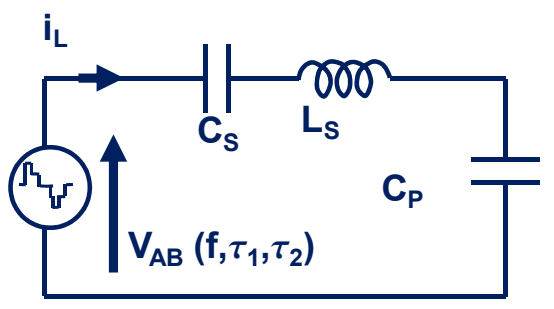

Radiography

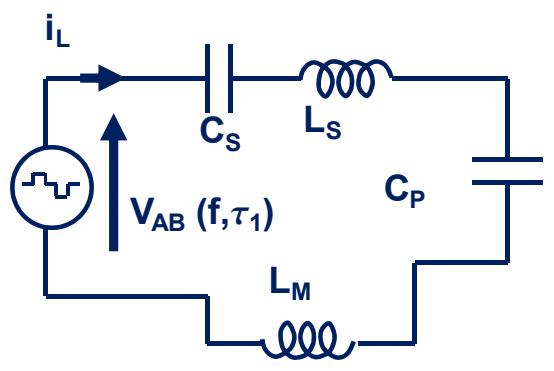

Fluoroscopy

Fig. 7: Simplified model of the resonant mesh for high (left) and low-power (right) applications.

The differential equations of the resonant mesh are presented in (3) and (4), where $\mathrm{L}_{X}$ represents $\mathrm{L}_{S}$ or $\mathrm{L}_{\mathrm{S}}+\mathrm{L}_{\mathrm{M}}$ depending on the case. " $\mathrm{r}$ " concentrates in a single resistor the power losses of the resonant circuit.

$$
\begin{aligned}
& V_{A B}(t)=V_{S}(t)+V_{P}(t)+L_{X} \cdot \frac{d i_{L}(t)}{d t}+r \cdot i_{L}(t) \\
& C_{S} \cdot \frac{d V_{S}(t)}{d t}=i_{L}(t)
\end{aligned}
$$

Behind the high-voltage output rectifier there is a second mesh that must be analyzed too. In this case, Kirchoff's current low is applied to obtain (5). The current through the rectifier, iD, is divided between the output capacitor, $\mathrm{C}_{\mathrm{F}}$, and the load, $\mathrm{R}$. Magnitudes in (5) have been transferred to the primary of the step-up transformer.

$$
i_{D}=C_{f} \frac{d V_{x}(t)}{d t}+\frac{V_{x}(t)}{R}
$$

These three differential equations (3-5) describe the dynamic model of the topology. Hence, they are the state equations. They include three variables that store a significant amount of energy: $V_{S}, V_{X}$ and $i_{L}$, i.e., the state variables. As the variation of energy is important in the circuit state analysis, their time-derivatives appear explicitly in the state equations. Bearing in mind the resonant circuit waveforms, it is evident that in (3) and (4) the predominant effects on the circuit will be produced by the first harmonic component. Therefore, the related state variables can be approximated as shown in (6) and (7). However, in the output section, behind the rectifier, the waveforms must be approximated by their mean value. In fact, this is the prevailing harmonic term in all the variables which appears in (5). This fact is expressed in (8), where the magnitude $\mathrm{V}_{\mathrm{x} 2}$ has been referred to primary side.

$$
\begin{aligned}
& i_{L}(t) \approx i_{L A} \cdot \operatorname{Sin}(\omega \cdot t)+i_{L B} \cdot \operatorname{Cos}(\omega \cdot t) \\
& V_{S}(t) \approx V_{S A} \cdot \operatorname{Sin}(\omega \cdot t)+V_{S B} \cdot \operatorname{Cos}(\omega \cdot t) \\
& V_{x}(t) \approx V_{\text {xavg }}(t)
\end{aligned}
$$


It should be noted that although $V_{P}$ is the voltage of a capacitor, the energy it represents is not significant. In fact, that voltage cannot vary freely. On the contrary it is clamped twice every period, when the output rectifier is on, by the voltage at $\mathrm{C}_{\mathrm{f}}$, a quite higher capacitance. This process is presented in fig. 8. The output rectifier operates in discontinuous conduction mode, being disconnected every time the resonant current, iL, changes its sign. Then iL flows through $\mathrm{C}_{\mathrm{P}}$, making it start to charge sinusoidally. After some time, its voltage, $\mathrm{V}_{\mathrm{P}}$, reaches the value of the output voltage at $\mathrm{C}_{\mathrm{f}}$, and the rectifier is on again. Now $\mathrm{C}_{\mathrm{f}}$ and $\mathrm{CP}$ are connected in parallel. Given the large capacitance of $\mathrm{C}_{\mathrm{f}}$, the resonant current can hardly change the voltage across this capacitor, and it can be assumed to be constant: $V_{P}$ is clamped. The conduction angle of $\mathrm{C}_{\mathrm{P}}$ in a period, $\psi$, can be deduced from the differential equation of a charging

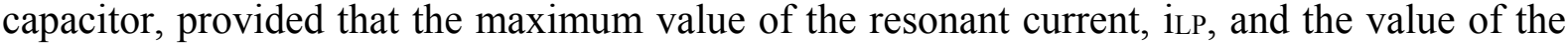
output voltage referred to the primary, $\mathrm{Vx}$ are known (9).

$\operatorname{Cos}(\psi)=1-\frac{2 C_{P} \omega \cdot V_{x}}{i_{L P}}=1-\frac{2 C_{P} \omega \cdot V_{x}}{\sqrt{i_{L A}^{2}+i_{L B}^{2}}}$

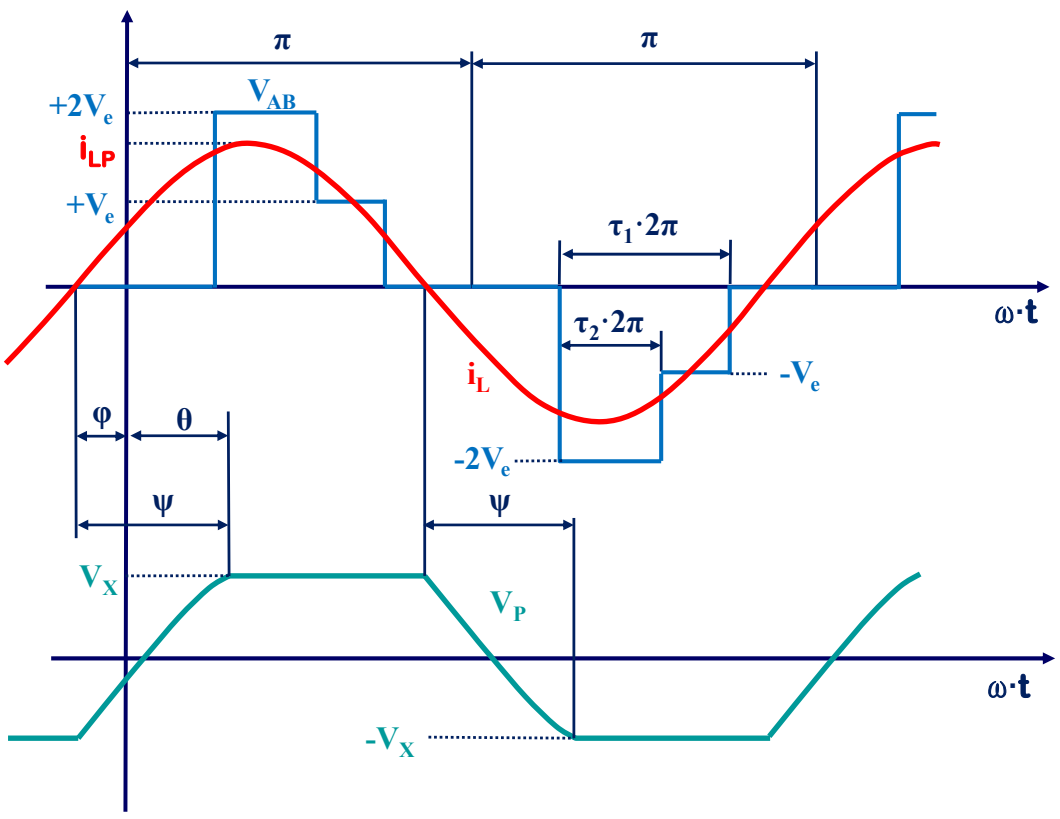

Fig. 8: Topology waveforms. Top: Output voltage of both inverters, VAB, and resonant current, iL. Bottom: voltage at the parallel capacitor, VP.

Once the clamping angle, $\psi$, is known, it is possible to determine the harmonic content of $V_{P}$ and $i_{D}$, referred to the primary. The suitable harmonic term is expressed in (10) and (11) respectively, being $\mu$ an abbreviation given in (12).

$V_{P}=\frac{i_{L A} \cdot \operatorname{Sin}^{2}(\psi)+i_{L B} \cdot \mu}{\pi \cdot C_{P} \omega} \cdot \operatorname{Sin}(\omega t)+\frac{-i_{L A} \cdot \mu+i_{L B} \cdot \operatorname{Sin}^{2}(\psi)}{\pi \cdot C_{P} \omega} \cdot \operatorname{Cos}(\omega t)$

$i_{D}(t) \cong \frac{i_{L}}{\pi} \cdot[1+\operatorname{Cos}(\psi)]$

$\mu(\psi)=\psi-\operatorname{Sin}(\psi) \cdot \operatorname{Cos}(\psi)$

Finally, the harmonic approximation of $\mathrm{V}_{\mathrm{AB}}$, is obtained too. The expression of its first Fourier coefficient is given in (13-15), being $\tau 1$ the duty cycle of the main inverter and $\tau 2$ the 
duty cycle of the auxiliary inverter. If the transferred power is low enough, this auxiliary inverter is not operating. In this case, (13) and (14) are still valid if $\tau 2$ is considered null.

$$
\begin{aligned}
& V_{A B}(t) \approx V_{A B 1 S} \cdot \operatorname{Sin}(\omega t)+V_{A B 1 C} \cdot \operatorname{Cos}(\omega t) \\
& V_{A B 1 S}=\frac{2 V_{e}}{\pi}\left[3 \cdot \operatorname{Sin}\left(\pi \tau_{1}\right)-\operatorname{Sin}\left(\pi\left(\tau_{1}-2 \tau_{2}\right)\right)\right] \\
& V_{A B 1 C}=-\frac{2 V_{e}}{\pi}\left[\operatorname{Cos}\left(\pi \tau_{1}\right)-\operatorname{Cos}\left(\pi\left(2 \tau_{2}-\tau_{1}\right)\right)\right]
\end{aligned}
$$

At this moment, the state equations (3-5) can be reconsidered to substitute the state variables (6-8), $V_{P}(10)$, iD (11) and $V_{A B}$ (14-15) for their suitable harmonic approximation. By doing so, the large signal dynamic model of the system is approximated by a simpler, but accurate enough, mathematical expression (16-20). After the substitution, the summands of (3) and (4) contain sine and cosine terms, which can be grouped. This way, both equations (3) and (4) are split into two. That is why the large-signal model is expressed as 5 differential equations (1620) instead of three (3-5).

$$
\begin{aligned}
& \frac{d i_{L A}(t)}{d t}=\frac{1}{L_{S}}\left[\begin{array}{l}
\frac{2 V_{e}}{\pi}\left[3 \cdot \operatorname{Sin}\left(\pi \tau_{1}\right)-\operatorname{Sin}\left(\pi\left(\tau_{1}-2 \tau_{2}\right)\right)\right]+ \\
L_{x} \omega \cdot i_{L B}-V_{S A}-\frac{i_{L A} \cdot \operatorname{Sin}^{2}(\psi)+i_{L B} \cdot \mu}{\pi \cdot C_{P} \omega}-r \cdot i_{L A}
\end{array}\right] \\
& \frac{d i_{L B}(t)}{d t}=\frac{1}{L_{S}}\left[\begin{array}{l}
-\frac{2 V_{e}}{\pi}\left[\operatorname{Cos}\left(\pi \tau_{1}\right)-\operatorname{Cos}\left(\pi\left(2 \tau_{2}-\tau_{1}\right)\right)\right] \\
-L_{x} \omega \cdot i_{L A}-V_{S B}+\frac{i_{L A} \cdot \mu-i_{L B} \cdot \operatorname{Sin}^{2}(\psi)}{\pi \cdot C_{P} \omega}-r \cdot i_{L B}
\end{array}\right] \\
& \frac{d V_{S A}(t)}{d t}=\frac{1}{C_{S}}\left[i_{L A}+C_{S} \omega \cdot V_{S B}(t)\right] \\
& \frac{d V_{S B}(t)}{d t}=\frac{1}{C_{S}}\left[i_{L B}-C_{S} \omega \cdot V_{S A}(t)\right] \\
& \frac{d V_{\text {xavg }}(t)}{d t}=\frac{1}{C_{f}}\left[\frac{i_{L}}{\pi}[1+\operatorname{Cos}(\psi)]-\frac{V_{\text {xavg }}}{R}\right]
\end{aligned}
$$

The harmonic approximation has changed the nature of the state variables. Originally they represented the temporal evolution of the waveforms. Now, after the approximation, they just represent the amplitude and phase of the sinusoidal variables $i_{L}$ and $V_{S}$, and the average value of the output voltage, $\mathrm{Vx}$. Some information is lost but the important one remains.

\section{Steady state model}

The steady-state model can be easily derived from the large-signal model. It is only necessary to consider that under steady state condition the variables do not change from one period to other. Mathematically, this means that the derivatives of the model (16-20) are zero. After this consideration and simple algebraic manipulation the steady state model is obtained (21-25). The subscript 0 indicates particularization for static operation.

$$
\begin{aligned}
i_{L A 0} & =\frac{-V_{A B 1 C} Z_{I}+V_{A B 1 S} Z_{R}}{Z_{R}{ }^{2}+Z_{I}{ }^{2}} \\
i_{L B 0} & =-\frac{V_{A B 1 S} Z_{I}+V_{A B 1 C} Z_{R}}{Z_{R}{ }^{2}+Z_{I}{ }^{2}}
\end{aligned}
$$




$$
\begin{aligned}
& Z_{R}=r+\frac{\operatorname{Sin}^{2}\left(\psi_{0}\right)}{\pi \cdot C_{P} \omega_{0}} \\
& Z_{I}=L_{x} \omega_{0}-\frac{1}{C_{S} \omega_{0}}-\frac{\mu_{0}}{\pi \cdot C_{P} \omega_{0}} \\
& V_{x 0}=R \frac{\sqrt{i_{L A 0}^{2}+i_{L B 0}^{2}}}{\pi}\left[1+\operatorname{Cos}\left(\psi_{0}\right)\right]
\end{aligned}
$$

The same equations (21-25) are also obtained if the circuit from fig. 9 is solved. It is the equivalent circuit of the topology at steady state.

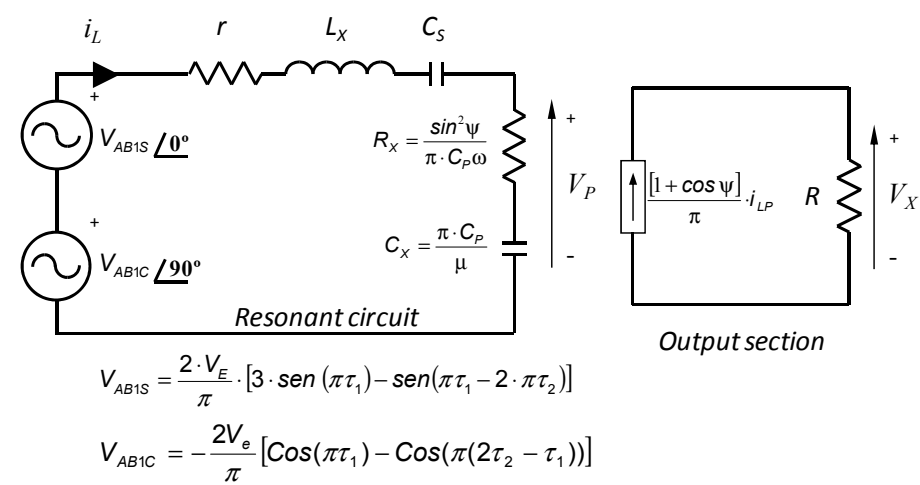

Fig. 9: Equivalent circuit for the topology under steady state condition.

\section{Experimental verification}

In order to check the accuracy of the mathematical model obtained, a scaled prototype is designed and assembled. The values of the resonant parameters are: $\mathrm{Ls}=38 \mu \mathrm{H}, \mathrm{Cs}=330 \mathrm{nF}$, and $\mathrm{Cp}=220 \mathrm{nF}, \mathrm{Lm}=125 \mu \mathrm{H}$. For validation purposes, a scaled input voltage has been used (40 to $75 \mathrm{~V}$ ). The step up transformer has also been removed, and resonant network has been implemented by discrete elements. Note that, in this prototype, voltage and current are divided by a scale of 10 and power by 100 . Table I compares the results provided by the prototype and the model.

Table I: Experimental results vs. the calculations obtained from the model (shaded)

\begin{tabular}{|l|c|c|c|}
\hline & $\mathrm{V}_{\mathrm{X}}(\mathrm{V})$ & $\mathrm{i}_{\mathrm{LP}}(\mathrm{A})$ & $\mathrm{P}_{\mathrm{SAL}}(\mathrm{W})$ \\
\hline Meas. 1 & $V_{x}=118.9$ & $I_{L}=22.7$ & $P_{w}=942.4$ \\
$\mathrm{~V}_{\mathrm{E}}=40 \mathrm{~V}$ & $V_{x}=119.8$ & $I_{L}=22.1$ & $P_{w}=956.8$ \\
\hline Meas. 2 & $V_{x}=59.4$ & $I_{L}=30.4$ & $P_{w}=940.8$ \\
$\mathrm{~V}_{\mathrm{E}}=40 \mathrm{~V}$ & $V_{x}=60$ & $I_{L}=29.39$ & $P_{w}=960.3$ \\
\hline Meas. 3 & $V_{x}=59.4$ & $I_{L}=30.4$ & $P_{w}=940.8$ \\
$\mathrm{~V}_{\mathrm{E}}=40 \mathrm{~V}$ & $V_{x}=60$ & $I_{L}=29.39$ & $P_{w}=960.3$ \\
\hline Meas. 4 & $V_{x}=64.2$ & $I_{L}=17.6$ & $P_{w}=549.5$ \\
$\mathrm{~V}_{\mathrm{E}}=60 \mathrm{~V}$ & $V_{x}=62.4$ & $I_{L}=17.9$ & $P_{w}=519.1$ \\
\hline Meas. 5 & $V_{x}=96.2$ & $I_{L}=5$ & $P_{w}=9.25$ \\
$\mathrm{~V}_{\mathrm{E}}=40 \mathrm{~V}$ & $V_{x}=95.6$ & $I_{L}=4.86$ & $P_{w}=9.13$ \\
\hline Meas. 6 & $V_{x}=32.21$ & $I_{L}=1.7$ & $P_{w}=1.037$ \\
$\mathrm{~V}_{\mathrm{E}}=40 \mathrm{~V}$ & $V_{x}=31.89$ & $I_{L}=1.66$ & $P_{w}=1.01$ \\
\hline
\end{tabular}


Measurements 1-4 are obtained when both inverters are operating. Measurements 5-6 are obtained when the auxiliary inverter is off. Experimental waveforms for both cases are shown in fig. 10. The oscilloscope channels have been used according to the following criteria: Ch1, yellow, output voltage, Vx. Ch2, green, resonant current iL. Ch3, purple, auxiliar inverter voltage, VB. Ch4, red main inverter voltage, VA. Math channel, pink, resonant circuit voltage, $\mathrm{V}_{\mathrm{AB}}$. The difference between the measurements on the prototype and the calculation provided by the model is always below $3 \%$.

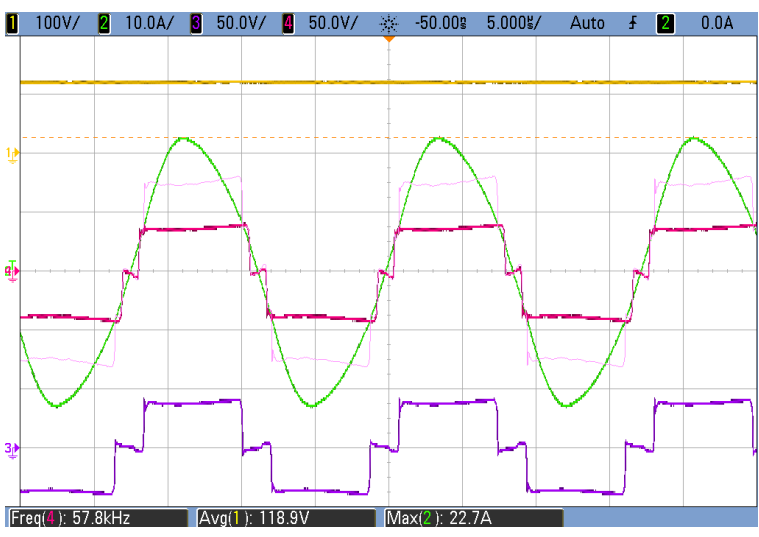

a) Waveforms at measurement 1 .

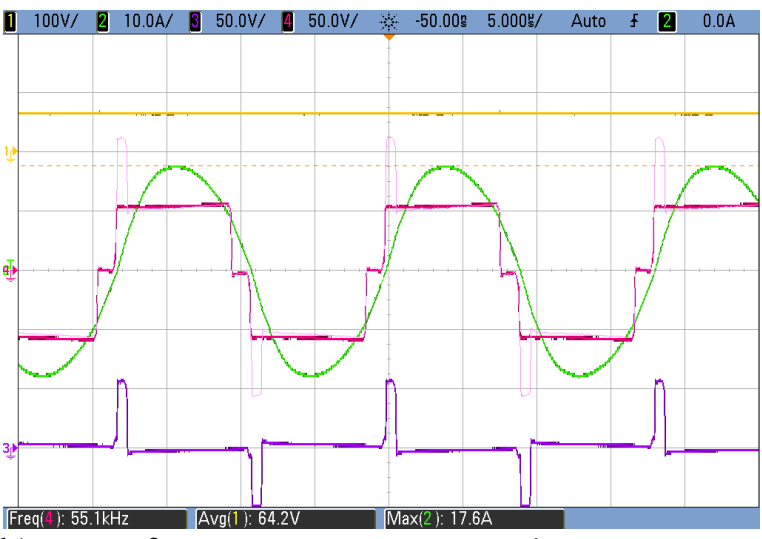

b) Waveforms at measurement 4 .

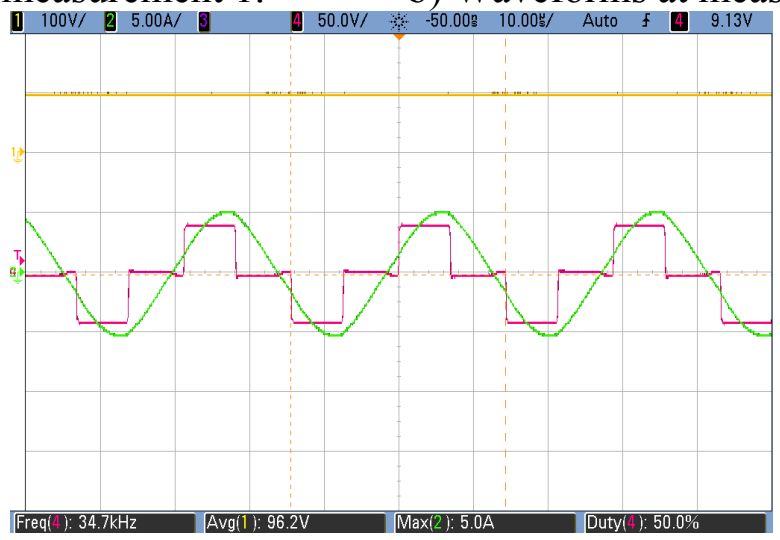

c) Waveforms at measurement 5

Fig. 10: Experimental waveforms for the inverters at measurement 5.

\section{Conclusions}

In this paper a novel resonant topology based on a multilevel structure is studied. It is formed by two full-bridge inverters coupled through a transformer. They have the ability to compensate input voltage fluctuations to produce the same first harmonic in their output square voltage. The result is that the resonant stage can be designed more conveniently for a particular application, halving expected current levels. Moreover, at low power levels (fluoroscopy) one of the inverters can be deactivated, so that the power circuit is favorably changed for those conditions. Other interesting contribution is the reduction of the inverter switching losses at high input voltage levels. Although the number of switches has been doubled, their current rating is halved.

As a design tool, a large signal dynamic model for the topology has been deduced step by step. This model is particularized for steady state condition. Its validity and accuracy has been experimentally demonstrated. 


\section{References}

[1] Z. De Greve, O. Deblecker, J. Lobry "Numerical Modeling of Capacitive Effects in HF Multiwinding Transformers - Part I: A Rigorous Formalism Based on the Electrostatic Equations” IEEE Trans. On Magnetics. Vol. 49, n 5, pp. 2017-2020, May 2013

[2] J. Biela, J. W. Kolar, "Using transformer parasitics for resonant converters-A review of the calculation of the stray capacitance of transformers," IEEE Trans. Industry Applications, vol. 44, no. 1, pp. 223233 Jan 2008

[3] P. Ranstad, H.P. Nee "On the distribution of AC and DC winding capacitances in high frequency transformers with rectifier loads” IEEE Trans. On Industrial Electronics Vol. 58, n5 pp 1789-1798 May 2011

[4] Robert L. Steigerwald “ A comparision of half-bridge resonant converter topologies” IEEE Transaction on Power Electronics, Vol. $3 \mathrm{~N}^{\mathrm{o}} 2$ April 1988

[5] S.D. Johnson, A.F. Witulsky, R.W. Erickson "A comparison of resonant topologies in high voltage DC applications” IEEE Trans. On Aerospace and Electronic Systems Vol. 24 n3 May 1988

[6] Ashoka K. S. Bhat. "Analysis and Design of a Series Parallel Resonant Converter with Capacitive Output Filter”. IEEE Trans. On Industry Applications Vol. 27, n3 June 1991 pp-523-530

[7] V. García, M. Rico, J. Sebastián, M Hernando and J. Uceda. “An Optimized DC-DC Converter Topology for High Voltage Pulse Loads Applications” IEEE PESC 94 pag. 1413-1421.

[8] J. Martin-Ramos, A. M. Pernía, J. Diaz, F. Nuño, J. A. Martínez. "Power Supply for a High Voltage Application.”. IEEE Trans. On Power Electronics Vol. 23, n4 July 2008 pp-1608-1619

[9] C. Iannello, S. Luo, and I. Batarseh, "Full bridge ZCS PWM converter for high-voltage high-power applications," IEEE Trans. Aerosp. Electron. Syst., vol. 38, no. 2, pp. 515-526, Apr. 2002

[10] V. García, M. Rico, J. Sebastián, M Hernando "Using the Hybrid Series Parallel Resonant Converter with Capacitive Output Filter and PWM Phase- Shifted Control for High- Voltage Applications”. IEEE IECON'94 pages 1659-1664

[11] Chr. Loef "Analysis of a full bridge LCC-type parallel resonant converter with capacitive output filter" IEEE PESC 97, pag 1402-1407

[12] G. Ivensky, A. Kats, S. Ben-Yaakov “An RC Load Model of Parallel and Series Parallel DC-DC Converters with Capacitive Output Filter” IEEE Transaction on Power Electronics, Vol. 14 No 3 May 1999, pp $515-521$

[13] J. Martin-Ramos, J. Diaz, A. M. Pernía, J.M. Lopera, F. Nuño. "Dynamic and Steady State Models for the PRC-LCC topology witha a Capacitor as Output Filter". IEEE Trans. On Industrial Electronics Vol. 54 n4 August 2007 pp- 2262-2275.

[14] R. Yang, H. Ding, Y. Xu, L. Yao and Y. Xiang “An Analytical Steady State Model of LCC type SeriesParallel Resonant Converter with Capacitive Output Filter” IEEE Trans. On Power Electronics Vol. 29 n1 Jan 2014 pp- 328-338

[15] S. Gavin, M. Carpita, P. Ecoeur, H. P. Biner, M. Paolone, E. T. Louokdom “A Digitally Controlled $125 \mathrm{kVdc}, 30 \mathrm{~kW}$ Power Supply with an LCC Resonant Converter Working at Variable DC-Link Voltage: Full Scale Prototype Test Results". PEMD, Enero 2014 pp 1.4.03.

[16] M. Hu, N. Froehlekw, W. Peters, J. Boecker "Multi-Objective Optimization of LCC Resonant Converter Applied in VLF HV Generator" IECON Nov. 2011, pp- 1456-1461

[17] J. Martin-Ramos, P. J. Villegas, A. M. Pernía, J. Díaz, J. A. Martinez. “Optimal Control of a High Voltage Power Supply based on the PRC-LCC topology with a Capacitor as Output Filter". Trans. on Industry Applications, Vol. 49, n 5, pp 2323-2329, May 2013

[18] J.M. Sun, S.P. Wang, T. Nishimura and M. Nakaoka " Resonant Mode PWM DC-DC Converter with a high-voltage transformer link and its control methods for medical-use X-ray power supply” EPE'99 Lausanne

[19] R. Casanueva, C. Brañas, F.J. Azcondo, F.J. Díaz "Teaching resonant converters: Properties and applications for variable loads” IEEE Trans. On Industrial Electronics Vol. 57 n10, pp 3355-3363, Oct 2010

[20] N. Shafiei, M. Pahlevaninezhad, H. Farzanehfard, S.R. Motahari "Analysis and Implementation of a Fixed-Frequency LCLC resonant converter with capacitive output filter" IEEE Trans. On Industrial Electronics, Vol. 58, n-10, pp 4773-4782 Oct-2011

[21] J.A. Martín-Ramos, Ó. Pardo-Vaquero, P.J. Villegas, J.A. Martínez, A.M. Pernía "Multilevel PRC-LCC resonant converter for X-ray generation” IET Electronic letters 23rd July 2015 Vol. 51 No. 15 pp. 1189-1191 